\title{
Atualidade de Paulo Freire ${ }^{1}$ \\ Paulo Freire Timeless
}

\author{
Balduino Antonio Andreola \\ balduino@unilasalle.edu.br \\ Gomercindo Ghiggi \\ gghiggi@terra.com.br
}

\begin{abstract}
Resumo
A atualidade de Paulo Freire pode ser avaliada a partir de diferentes indicadores, entre eles, o das instituições, no Brasil e no mundo, dos grupos e movimentos que promovem pesquisas, ações e projetos, nos campos da educação e desenvolvimento humano em geral. No Rio Grande do Sul, a XV sessão anual do Fórum de Estudos: Leituras de Paulo Freire, realizada em 2013, teve mais de duzentos trabalhos apresentados. O VIII Colóquio Internacional do Centro Paulo Freire de Estudos e Pesquisas, de Recife, teve participação ainda mais ampla. O Instituto Paulo Freire de São Paulo, é outro exemplo da atualidade do autor. Pedagogia do oprimido, tem hoje 50 edições e está traduzido em mais de 20 línguas, Educação como prática da liberdade está na 34ª edição e Pedagogia da autonomia, na 43ํ. Pedagogia do oprimido é mais que um livro, um projeto a serviço de um mundo mais solidário, e foi recriado de muitas maneiras, no mundo inteiro, nos campos da educação, da ética, da ecologia, da saúde, da cultura e da política.

Palavras-chave: Educação, Ecologia, Ética, Libertação, Universalidade, Reconhecimento mundial
\end{abstract}

\begin{abstract}
The timeless of Paulo Freire can be evaluated from different indicators. One of them, the institutions in Brazil and over the world, of groups and movements that promote research, actions and projects in the fields of education and human development in general. In Rio Grande do Sul, the Forum of Studies: Readings of Paulo Freire, hosted each year by a different institution of higher education, held in 2013 its XV annual session with the presentation of over two hundred works. The VIII International Colloquium at Paulo Freire Center of Studies and Research of Recife took place this year with a much broader participation. The Instituto Paulo Freire of São Paulo, with a wide range of promotions and publications, is another example among us of the timeless of Freire. With regard to the dissemination of his works in Brazil, we just remember the number of editions of four of his books: 50 of Pedagogy

\footnotetext{
${ }^{1}$ Contribuíram para a elaboração deste artigo: Ronaldo Silva Lopes, graduando em psicologia no Unilasalle, bolsista no projeto "Por uma pedagogia das grandes urgências e das grandes convergências"; Douglas Souza Angeli, graduado em história pelo Unilasalle e mestrando em história pela UNISINOS; e Silvia Adriana da Silva Soares, graduada em pedagogia pelo Unilasalle (2011), secretária do Pós-Graduação Stricto Sensu do Centro Universitário La Salle. silvia@unilasalle.edu.br.
} 
of the oppressed, 34 of Education as practice of freedom, 34 of Education and change, and 43 of Pedagogy of autonomy.

Pedagogy of the oppressed is translated into more than twenty languages. Roger Pedagogy of the oppressed is not a book, it is a project in the service of a more caring world and, as such, recreated in many ways, by thousands of educators and millions of people throughout the world, in the fields of education, ethics, ecology, health, culture and politics, as he has written that we must "reinvent the power".

Keywords: Education, Ecology, Ethics, Liberation, Universality, Worldwide recognition

Balduino - Para falar da atualidade de Paulo Freire, julgo oportuno começar por um dos aspectos fundamentais de sua obra e de toda a sua longa trajetória de educador. Trata-se da dialogicidade, talvez o conceito mais importante de toda a sua elaboração teórica, e do diálogo como exercício constante de sua práxis pedagógico-política, ao longo de toda a sua vida. Ele vivia o diálogo, em todos os seus contatos, como exigência ontológica da existência humana, a mais importante de todas. Ele o praticava em suas aulas, palestras ou conferências. Prolongava-o em cartas numerosas e até em livros (quatro), que trazem no título, como compromisso, o vocábulo "Cartas". Até o fim, enquanto o livro que estava escrevendo intitulava-se Cartas Pedagógicas. Escreveu duas inteiras, e a terceira deixou-a inconclusa, em cima de sua mesa. Mesmo inconclusa, é um grito veemente contra a barbárie do assassinato de Galdino da Silva, o índio pataxó que repousava deitado num banco em Brasília. Além disso, uma das formas mais eloquentes de praticar o diálogo foi a produção de uns vinte livros, em diálogo com outros educadores.

Nessa forma de se comunicar e de escrever, Freire teve predecessores muito famosos. Sócrates, que não escreveu nenhum livro, praticou o diálogo o tempo todo, em suas preleções filosóficas. Seu discípulo Platão escreveu toda a sua volumosa obra em livros dialogados, sendo sempre Sócrates o interlocutor principal. Lembrarei ainda dois outros pensadores platônicos insignes, Santo Agostinho e Santo Anselmo de Cantuária, que nos deixaram obras memoráveis, escritas sob a forma de diálogo. Esses exemplos famosos de diálogo justificam minha opção por escrever este artigo, num diálogo, via Internet, com um exímio estudioso da obra de Paulo Freire, o professor Gomercindo Ghiggi, docente da Faculdade de Educação da Universidade Federal de Pelotas - UFPel. 
Como provocação para o diálogo, formularei algumas perguntas, que muitas pessoas poderiam fazer, ao ler o título acima. O próprio tema proposto pode ser formulado como pergunta: Paulo Freire é atual? Numa pesquisa de opinião, obteríamos grande variedade de respostas? Haveria convergência, de respostas afirmativas, ou não? O que pensas de tudo isso, meu caro colega Gomercindo?

Gomercindo - Caro professor Balduíno, mais uma vez provocas para que dialoguemos, neste momento, sobre a atualidade do legado de Paulo Freire. Diversos são os questionamentos que brotam das tuas provocações acima. Com certeza, como bem afirmas, diversas poderiam ser as respostas. Considerando que lembraste as Cartas Pedagógicas, que Freire estava escrevendo antes de sua partida, ouso dizer que os temas abordados por ele nas Cartas, últimos escritos em 1997, expressam a sua importância para a educação, o seu legado à sociedade no seu conjunto e as urgências do nosso tempo. A centralidade é a indignação: "Cinco adolescentes mataram hoje, barbaramente, um índio pataxó, que dormia tranquilo [...]. Disseram à polícia que estavam brincando". A indignação com a brincadeira de jovens, ao não saberem o que fazer com tanta liberdade que presumem ter, revela temas com os quais Freire se ocupou na fase final de sua vida. Para Freire (2000), a indignação é central, para que se possa trabalhar com o "acatamento ao outro, o respeito ao mais fraco, a reverência à vida não só humana, mas vegetal e animal, o cuidado com as coisas, o gosto da boniteza, a valoração dos sentimentos [...]" (p. $66)$.

$\mathrm{Na}$ sua indignação, Freire denuncia aquele ato de extrema violência como "trágica transgressão da ética" que, segundo ele, "nos adverte de como urge que assumamos o dever de lutar pelos princípios éticos mais fundamentais, como 0 respeito à vida dos seres humanos, à vida dos outros animais, à vida dos pássaros, à vida dos rios e das florestas" (FREIRE, 2000, p. 66-67). O tema da ética, como respeito e defesa de todas as formas da vida, afirmado aqui com a veemência total de sua indignação, foi talvez o tema-chave, que perpassa seu livro Pedagogia da autonomia (1997), da primeira à última página. Aqui, ele o retoma conclamando-nos a assumi-lo numa dimensão de "urgência". Como defesa da vida, em todas as suas formas, ele associa a ética à ecologia, declarando: "A ecologia ganha uma importância fundamental neste fim de século" (2000, p. 67). Mas a ética e a 
ecologia não podem prescindir da educação, se com ele concordamos que "Se a educação sozinha não transforma a sociedade, sem ela tampouco a sociedade muda" (FREIRE, 2000, p. 67). Nunca foi feita, quiçá, uma síntese articuladora tão evidente, entre "ética, ecologia e educação", como nesse fragmento final da Terceira Carta, que Freire nos deixou inacabada, sobre sua mesa. Mas, voltemos, Balduino, à pergunta sobre a atualidade de Freire. Afinal de contas, Paulo Freire é ou não atual?

Balduino - De uma coisa tenha certeza: não haveria, nem de longe, unanimidade positiva de respostas. Muitos, inclusive, questionariam o sentido da pergunta. $\mathrm{O}$ que significa, afinal, atualidade de um autor, de uma obra, de uma teoria? Nesse sentido, eu mesmo poderia responder de várias maneiras. Uma delas seria dizer que o próprio Paulo Freire se desatualizou quando, numa de suas últimas entrevistas, disse: "Os problemas são tantos e tamanhos, que eu não poderia ter respostas ou soluções para os mesmos. Cabe a vocês inventar novas pedagogias". Não disponho de referência escrita dessa declaração. Quem me contou foi o professor Ernesto Jacob Kheim, de Blumenau. Poderíamos interpretar a declaração de Freire, desdobrando-a, para dizer que nenhum dos grandes educadores da humanidade quis ser repetido. Todos nos lançaram grandes desafios e sugeriram pistas, para que seus discípulos ou leitores construíssem novos caminhos, formulassem novas ideias e novas estratégias pedagógico-políticas de ação. Nessa ótica, as obras dos grandes pensadores e das grandes pensadoras, em todos os campos do conhecimento, continuam atuais, porque, na leitura das mesmas, nos confrontamos de novo com o desafio de pensarmos, crítica e criativamente, os problemas, na busca por respostas que os novos tempos e novos contextos demandam.

$\mathrm{Na}$ variedade das respostas, nos depararíamos também com algumas (ou muitas?) inteiramente negadoras de qualquer atualidade da obra de Freire, formuladas em expressões como esta: "Paulo Freire já era". E não são raras essas respostas. Eu diria que não é o caso de estranharmos. Lembro ter sido essa a reação de Jean-Marie Domenach (1970), terceiro diretor da Esprit. Respondendo aos que consideravam superados Mounier e o personalismo, sua ponderação foi: "É com razão que se xinga a sociedade de consumo, na medida em que se devoram 
tanto as palavras quanto as teorias. No ritmo em que andamos, Paris lança uma nova moda intelectual cada três ou quatro anos" (p. 646).

Realmente, foram moda o marxismo, depois o existencialismo, seguido pelo estruturalismo e assim por diante. Não sabemos se o pós-moderno é modismo ou, quiçá, pós-modismo. Sobre esse descarte de teorias diante das novidades, o antropólogo Clifford Geertz (1989), na parte inicial de seu livro $A$ interpretação das culturas, salientou: "A segunda lei da termodinâmica ou o princípio da seleção natural, a noção de motivação inconsciente ou a organização dos meios de produção não explicam tudo, nem mesmo tudo que é humano, mas ainda assim explicam alguma coisa" (p. 3).

Mounier (1961, p. 44-45), por sua vez, escreveu que as grandes filosofias, longe de se contraporem, se complementam. Poderíamos acrescentar, fiéis ao seu pensamento, que as diferentes filosofias ou, quem sabe, teorias científicas ou pedagógicas, representam diferentes olhares sobre a paisagem multifacetada e multicolorida da existência humana e do mundo.

O problema não é tanto o desatualizar, mas, sim, o condenar ao esquecimento, que parece constituir-se numa tendência quase inata da cultura, ou melhor, da anticultura brasileira, analisada por mim, como uma expressão de colonialismo intelectual, vigente em muitas universidades (ANDREOLA, 2007, p. 4572). Quem denuncia com veemência essa síndrome brasileira do esquecimento é Afrânio Coutinho (1999), que, ao prefaciar um dos livros de Anísio Teixeira, escreveu:

Sempre que consideramos a vida dos grandes homens do Brasil, chegamos a um profundo sentimento de frustração. [...] As grandes ideias, as grandes propostas [...] não germinam, não florescem, não frutificam. [...] No fundo, o pensamento é este: este fulano deve ser preso, ele quer fazer coisas, lá vem ele com novidades. Não pode. Está tudo tão bem. Anísio Teixeira foi uma vítima desse espírito. (p. 13-14)

Ao escrever sobre Ernani M. Fiori (Andreola, 2004), após citar o texto acima de Afrânio Coutinho, eu comentei:

Este fenômeno de memória necrófila com relação a grandes personalidades nossas foi oficializado, em vários momentos de nossa história, por regimes autoritários e repressores, na forma de ritos macabros de satanização, mediante os quais cidadãos e cidadãs eminentes, com atuação altamente reconhecida, como intelectuais, artistas políticos ou lideranças populares, foram julgados como traidores, destituídos de suas funções e condenados ao cárcere, ao exílio ou então ao anonimato dos cemitérios clandestinos. Isso não é imaginação, são fatos sobejamente conhecidos. (p. 215) 
O próprio Fernando Henrique Cardoso reconhece esse mal da brasilidade e reage a essa mentalidade necrófila, com o livro Pensadores que inventaram o Brasil (2013), dedicado ao resgate da vida e das obras de grandes personalidades, que deram contribuições inesquecíveis para a construção de um Brasil que todos nós quereríamos. Pena que não tenha incluído em seu livro, nomes como os de Manoel Bomfim, Vieira Pinto, Paulo Freire, Anísio Teixeira e Darcy Ribeiro. Anísio, Darcy Ribeiro e outros pensadores ilustres da época, ao planejarem a Universidade de Brasília, se recusavam "a aceitar a universidade de mentira que se cultivava no país, tão inconsciente de si como contente consigo mesma" (RIBEIRO, 1986, p. 4), mas que fosse uma universidade capaz de pensar o Brasil como problema.

Ao ler um texto desse livro de Fernando Henrique, pensei que o que ele escreveu a respeito de Sérgio Buarque de Holanda valeria igualmente para os cinco brasileiros lembrados acima. Este é o texto: "Sérgio Buarque interpreta, sintetizando, analisando, instruindo e apontando alternativas. E é por isto, porque o autor inova ao recolocar o passado e não o estiola pela ausência de perguntas sobre o futuro, que Raízes do Brasil é um clássico. Como todo clássico, o livro de Sérgio mantém a atualidade" (CARDOSO, 2013, p. 140).

A Comissão da Verdade trará, tenho certeza, como um dos resultados mais importantes de sua difícil e relevante missão, o resgate da memória desses cidadãos e dessas cidadãs insignes, mas também o fabuloso patrimônio de ideias, de obras escritas e de realizações, nos diferentes campos do pensamento e da ação, a serviço da coletividade nacional e internacional.

Gomercindo - Lembrando Freire e sua capacidade de escuta, Balduino, vou saboreando contigo memórias, andarilhagens e o desvelamento de um mundo de acontecimentos, que marcam, historicamente, a presença de Freire nas nossas vidas, nas vidas de muitas pessoas envolvidas com educação e com a luta por uma sociedade radicalmente justa.

Balduino - Pois é, Gomercindo, vou então continuando com a exploração de "memórias esquecidas", de pensadores cujas contribuições me parecem atuais, na perspectiva de organização da sociedade, em tempos complexos como os que vivemos em 2013. Lembro, então, que, por ocasião do lançamento do II volume das 
obras de Ernani M. Fiori, em 1992, o filósofo João Carlos Brum Torres, da UFRGS, na mesma linha de Afrânio Coutinho lembrou, em sua fala:

O povo brasileiro, de memória tão volátil, que submete suas expressões à decisão permanente, à iconoclastia que passa por toda a parte, é um povo sem memória, que não adquiriu identidade, que não tem passado, que, por conseguinte, não pode ter futuro.

Naquela mesma ocasião, Paulo Freire, também participando da mesaredonda, louvou, em sua fala, a Editora L\&PM, pela iniciativa de publicar as obras de Ernani. Estas foram suas palavras: "Este é um gesto bonito, é um gesto sério, participar da luta gostosa de evitar que Ernani vire estátua, para que ele continue vivo, discutido, debatido, refeito, recriado, como vocês fazem".

A metáfora da "estátua", usada por Freire, lembra-me uma metáfora semelhante, usada em 1980, pelo Padre Ganne (apud ANDREOLA, 1985). Grande estudioso da obra de Mounier, ao proferir o discurso em homenagem àquele filósofo francês, por ocasião dos 20 anos de sua morte, ele declarou, ao concluir:

\footnotetext{
Podemos nos perguntar se o povo de Deus da atualidade não é tristemente fiel a uma de suas mais velhas "tradições": matar os profetas que the são enviados. E há várias maneiras de matar com eficácia, sendo as mais discretas e correntes o esquecimento, a desatenção, a ingratidão e, para coroar tudo, a construção de um monumento. (p. 98)
}

O tom das denúncias feitas por Afrânio Coutinho e João Carlos Brum Torres, de um "esquecimento" brasileiro quase como uma amnésia coletiva, leva-me a pensar que essa doença culturalmente mortal mereceria sérias análises, inspiradas talvez no livro monumental de Paul Ricoeur (2007) intitulado A memória, a história, o esquecimento. Naquela obra, o autor, cujo centenário de nascimento comemoramos neste ano, discorre longa e profundamente sobre o que ele denomina "excesso de memória" e, como contraponto igualmente deletéreo, "excesso de esquecimento", um esquecimento, em geral, comandado ou ideologicamente manipulado.

Ao falarmos de "atualidade de Paulo Freire", pareceu-me importante registrar, baseado nas citações de vários pensadores, o problema quase nacional, do esquecimento, não precisamente como atingindo a Freire, mas como uma deformação muito mais profunda e vasta, com relação à nossa memória histórica e à construção de nossa história. Com relação a Freire, parece-me que, por enquanto, o 
esquecimento não está acontecendo, uma vez que muitos se esforçam, muito mais no Brasil do que em outros países, para promovê-lo. E agora me permito trazer alguns fatos ou acontecimentos, ainda que nos limites de meus conhecimentos e de minha "memória", que revelam uma ampla difusão de sua obra, inspirando uma variedade imensa de práticas, eventos, estudos e publicações.

Neste ano de 2013, foi realizada, na FACCAT - Faculdades Integradas de Taquara, de 23 a 25 de maio, o XV Fórum de Estudos: Leituras de Paulo Freire, com a apresentação de mais de duzentos trabalhos. O Fórum foi criado em 1998, durante um congresso internacional, na UNISINOS. Ele é itinerante, sendo realizado cada ano numa instituição diferente de ensino superior do Rio Grande do Sul. Já foi sediado por cinco universidades federais, cinco comunitárias regionais, quatro comunitárias confessionais católicas, uma comunitária luterana e uma universidade estadual. As três últimas sessões do Fórum contaram também com o apoio oficial da CAPES.

Pelo Brasil afora, há outros grupos, movimentos ou centros que valorizam o estudo e a recriação da obra de Freire. Um dos mais conhecidos é, talvez, o "Centro Paulo Freire: Estudos e Pesquisas", do Recife, com o qual nosso Fórum mantém um diálogo fecundo. O Gomercindo e eu fomos convidados para, de 19 a 23 de setembro de 2013, participarmos em mesas-redondas e círculos de cultura, no VIII Colóquio Internacional. Não podemos esquecer o Instituto Paulo Freire, de São Paulo, com leque muito amplo de atividades e publicações. É impossível lembrar ou mapear, nos limites de um artigo, o número enorme de eventos, comemorações, homenagens e outras promoções, que vêm acontecendo, no Brasil e em vários outros países, desde que Paulo Freire nos deixou.

Gomercindo - Ao lembrarmos, Balduino, a nossa itinerância com o Fórum de Estudos: Leituras de Paulo Freire, talvez estejamos concretizando um pouco o que o próprio Freire apontou ao final de sua vida: a importância político-pedagógica das marchas. Depois de nos deixar, como último livro publicado em vida, Pedagogia da autonomia (1997), estava escrevendo outro, que traria o título Cartas pedagógicas, que não chegou a completar, como referimos anteriormente. Publicadas em 2000, juntamente com outros textos inéditos, pela esposa dra. Ana Maria Freire, trazem o título Pedagogia da indignação: cartas pedagógicas e outros escritos. O destaque 
"indignação" se deve talvez ao tom veemente de seu protesto contra violência e a barbárie, em sua última carta. E a "indignação" seria então, segundo Freire, um sentimento inicial necessário, numa busca da "autonomia". Foi também em suas Cartas finais que ele enfatizou o convite às "marchas".

Caro Balduino, Freire não viveu o desenvolvimento do capitalismo na virada do milênio, para ver a grande marcha que encontrou espaços na escola, por exemplo, ou ao se consolidar no discurso, nas universidades, nas marchas que parecem ser manifestações dos oprimidos. Isso impõe pensarmos que a leitura de Pedagogia do oprimido deve ser contínua, ao contrário de sua defesa sem reinvenção. E mirando nosso tempo histórico, com significativas parcelas da população caminhando pelas cidades e pelo campo do nosso Brasil, uma questão se impõe: as carimbadas marchas contemporâneas expressam resistências à nova pedagogia, produzida pelo hegemônico modelo capitalista, o projeto político da burguesia mundial? Pensamos que boa parte delas não, mas entendemos que existem possibilidades pedagógicas, que podem atuar no rumo da construção contra-hegemônica, através do que denominamos contramarcha. Ou seja, há uma nova pedagogia, que se apresenta não para contestar a pedagogia das marchas, mas para, então, reinventar a marcha indicada por Freire, qual seja, a marcha da humanização de todos os homens e todas as mulheres. A discussão aqui proposta, questionando universais e fragmentos, quando isolados, toma o caminho da educação popular enquanto campo capaz de articular a "unidade na diversidade", categoria central, em Freire, para aproximar educação e política.

Para se elaborar a indignação, Freire (2011) aponta as marchas como diretriz pedagógica e política, que ganha importância num tempo tomado por incertezas e vazios. O caminho indicado é juntar descobertas, reflexões singulares e escritos de autores diversos com as diversas leituras da realidade. Ou seja, Freire (2000) aponta o caminho das marchas ${ }^{2}$ como "ímpeto da vontade amorosa de mudar o mundo" (p. 60). O tema das marchas, portanto, pode ser apontado como um divisor de opiniões para o nosso tempo. Que pensas? Lembremos o tempo das manifestações pelo Brasil afora e questionemos: é o tempo das marchas indicado por Freire, dias antes de sua partida?

${ }^{2}<$ http://www.youtube.com/watch?v=MZQtP-7Ezbw>. Acesso em 5/10/2011.

Revista Educação Online no 14, p.89-104, ago./dez. de 2013. 
Balduino - Muito oportuna, Gomercindo, a lembrança do apoio de Freire às marchas e o convite a outras marchas. Tu falas tendo como referência a Pedagogia da Indignação. Nesse incentivo às "marchas", eu vejo a atualidade de Freire no que se refere aos movimentos sociais e, especificamente, às "marchas" que cabem a eles, na construção da democracia e de um mundo mais justo. Na Segunda carta pedagógica, que tu já citaste, depois de se referir à importância do MST e de outros movimentos históricos que o precederam, como os Quilombos e as Ligas Camponesas, Freire (2000) fala da grande marcha dos sem-terra a Brasília, provenientes de todos os recantos do país, e declara, com emoção:

E que bom seria para a ampliação e consolidação de nossa democracia, sobretudo para sua autenticidade, que outras marchas se seguissem à sua. A marcha dos desempregados, dos injustiçados, dos que protestam contra a impunidade, dos que clamam contra a violência, contra a mentira e o desrespeito à coisa pública. $\mathrm{A}$ marcha dos sem-teto, dos sem-escola, dos sem-hospital, dos renegados. A marcha esperançosa dos que sabem que mudar é possível. (p. 61)

Depois desta citação, podemos nos perguntar se Freire não é atual, como inspiração para compreendermos as "marchas" ou manifestações populares que estão acontecendo hoje, no Brasil inteiro. Elas não estão ocorrendo somente no Brasil, ainda que, em outras partes do mundo, insiram-se no contexto de outros movimentos, reclamando respeito à pessoa humana, mais justiça, mais democracia. Se muitos políticos não entenderam por que os manifestantes foram para as ruas, lendo o "manifesto" de Freire a favor das marchas, talvez descubram que, dezesseis anos atrás, antes de partir, como "andarilho da esperança", para a sua marcha definitiva, Freire já sabia o porquê, que eles, políticos, ainda não sabem.

Ao citar Freire no seu incentivo às marchas, cabe lembrar que ele próprio esteve perenemente em marcha, a caminho. Do Brasil para a Bolívia, brevemente, para o Chile, quase cinco anos, de lá para os Estados Unidos e, finalmente, para o Conselho Mundial de Igrejas, em Genebra, aonde se tornou cidadão e pedagogo do mundo. Num livro escrito em coautoria com o então meu orientando de doutorado em teologia, Mario Bueno Ribeiro, nós salientamos essa condição de universalidade, com o título Andarilho da esperança: Paulo Freire no C.M.I. (ANDREOLA, 2005). O meu coautor Mário Bueno Ribeiro manteve, em sua tese de doutorado, essa ideia com o título Andarilhagens pelo mundo: Paulo Freire no Conselho Mundial de Igrejas - CMI (2009). No anexo no 3 de sua tese, intitulado Itinerário de Paulo Freire - o andarilho da esperança (p. 178-193), ele apresenta fotocópias dos cronogramas das 
viagens de Paulo Freire, através de cinco continentes, durante os dez anos de Conselho Mundial. Na página 158, ele escreve: "A trajetória de Paulo Freire no CMI é marcada por intensidade tanto de viagens, quanto de produção teórica. Computamos aproximadamente 150 viagens de Paulo Freire, pelos cinco continentes" (RIBEIRO, 2009).

Todas essas viagens, e muitas outras, antes e depois desse período de dez anos no CMI, parecem-nos um comprovante do que escrevemos, Mário Bueno e eu, no livro citado, como título do sexto capítulo: Universalização da pedagogia do oprimido (p. 107-126). Universalização reconhecida já por Roger Garaudy (1977), quando em seu livro Para um diálogo das civilizações, considerava Paulo Freire, há mais de trinta anos, "o maior pedagogo do nosso tempo" (p. 198).

Acho interessante como o próprio Paulo Freire tomou consciência de sua universalidade, sem perder nunca sua proverbial modéstia. Numa longa entrevista com Miguel Darcy de Oliveira e Cláudius Ceccon, publicada no Pasquim (1978), a certa altura Claudius diz, num tom de pergunta: "De Recife para o Mundo". E Freire responde:

Não como a Rádio Jornal do Comércio. Mas é preciso também que se explique isso, porque parece muita falta de modéstia, um treco profundamente cabotino, falar de minha universalidade, como se eu fosse aqui um cara que se pensa um homem do mundo no sentido que se dá, quando se diz isso. Não, o que eu quero dizer é que sou, existencialmente, um bicho universal. Mas só sou, porque sou profundamente recifense, profundamente brasileiro. E por isso, comecei a ser profundamente latinoamericano e depois mundial. Eu sou capaz de querer bem, enormemente, a qualquer povo. (p. 10)

Em termos de difusão atual da obra de Paulo Freire, bastaria citarmos o número de edições alcançadas em 2013 de ao menos quatro livros: Pedagogia do oprimido, na 50ª edição; Educação como prática da liberdade, 34루; Pedagogia da

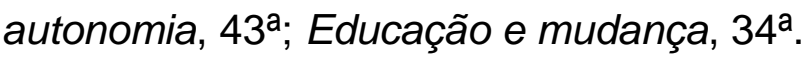

Gomercindo - Pois é, Balduino, mirando o conjunto das ideias que expusemos, e aqui indicando o fechamento, sempre inacabado, do nosso diálogo, fiquei com a pergunta: por que Paulo Freire é atual? E fui buscar nas minhas próprias memórias, razões que me aproximam de Freire, desde 1976. Parto da ideia de que Freire é um pensador que dá consistência à pedagogia crítica, ao fundamentar práticas coletivas. Fazendo-me acompanhar por McLaren (1999), compreendo que foi Freire 
que conseguiu ajudar, inclusive teóricos críticos, a reconhecer que a atividade pedagógica dominante, normalmente presente em escolas democráticas,

[...] estava firmemente acorrentada a uma ordem social liberal-capitalista que reproduz a desigualdade a nível ideológico, através do contrato lockeano, pelo qual relações assimétricas de poder são legitimadas sob a bandeira da agência autônoma e da livre competição no mercado capitalista. (p.28)

E aí, nos encontrando, mundo afora, na universidade, na escola e na vida, em Freire, porque quer que seu pensamento seja recriado; não quer discípulos nem seguidores, mas recriadores curiosos de suas próprias curiosidades. Fomos nos colocando em posição convergente com Torres (apud MCLAREN, 1998), quando afirma que "[...] é possível concluir que há boas razões pelas quais, na pedagogia da atualidade, podemos ficar com Freire ou contra Freire, mas não sem Freire" (p. 97). Torres desenvolve a afirmação, baseado em reflexões do próprio autor, defendendo que é fundamental realizar estudos sobre processos educacionais em Freire partindo "de [...] dupla perspectiva: usando a lente da classe hegemônica reprodução de relações sociais de produção - e usando a lente das classes subordinadas - educação como forma de construir uma nova hegemonia" (p. 97). Para o autor, a importância da educação está na reconstrução "da cultura do oprimido, particularmente através da noção de elaboração sistemática do conhecimento popular [...] como instrumento de luta da contra-hegemonia [...]" (p. 97).

A interferência na formação das pessoas, na perspectiva político-crítica que Freire aponta, dirige-se à exigência de que os ainda indignados com a organização social prepararem-se para assentar na contramão da história oficial, responsável pelo advento do novo que pode ocorrer na contradição e no diálogo com diferentes. A esperança de Freire, que a lemos desenhada em sua obra, é que as relações resistentes e combativas, fraternas e solidárias, também se globalizem.

Freire é principal ainda hoje para muitos de nós, porque, pensador do seu tempo, disponibiliza fundamentos para pensar a escola em contexto também no nosso tempo. É por isso que Freire dá o que pensar, colocando à disposição do mundo contemporâneo possibilidades de confrontos teórico-práticos referentes à totalidade das relações, o que torna fundamental a problematização de verdades absolutas. Defendemos a atualidade de Freire, porque ele busca refundamentar a educação em sua base epistemológica e ética, condição de possibilidade de 
exercício moral mínimo, com vistas ao que é ontologicamente máximo na relação social. É pensador e educador que põe em cena o sujeito da educação, não em perspectiva metafísica pura, mas na condição histórica em que vive, tornando-se intersubjetivo em suas relações de comunhão ou confronto com outros sujeitos, sempre em condições de sensibilidade à reciprocidade.

É assim que Freire, contra erudições em torno da negação da possibilidade de conscientizar alguém, é um pensador que mexe, neste nosso tempo, porque grava no coração de muitas pessoas mensagens de esperança e inconformismo permanente em relação à injustiça, iluminando caminhos sem precisar brilhar, ante intelectuais outros que brilham sem conseguir iluminar. Novamente buscando apoio em McLaren (1998), afirmamos a atualidade de Freire, porque

seu vocabulário filosófico permite ao mundo [...] adquirir visibilidade, permite-lhe inscrever-se como texto a empreender e a compreender [...]. É assim que o trabalho de Freire não reduz o mundo a um texto. Em vez disso, estipula as condições de possibilidade de discursos diversos, concorrentes e conflituais [...].(p. 66)

Freire nos ajuda a ver perspectivas de formação ao exercício da cidadania crítica, com competências para realizar intervenções sociais de forma autônoma e criativa, a partir do que a liberdade e a autonomia podem constituir.

Enfim, Freire, apontando para a marcha dos oprimidos e dos indignados, escreve com raiva e amor, sem o que não há esperança. Ele defende a tolerância, não o intolerável; critica o radicalismo; vivendo tempos em que se recusam o sonho e a utopia, resgata a formação crítica, na qual a história é fascinante aventura de desvelamento da verdade e não determinismo; critica a democracia quando não passa de espaço à democratização da sem-vergonhice; a esperança, dimensão ontológica humana, é o que teimosamente o coloca ante imperativos da existência histórica; ele crê na possibilidade do inédito viável, que desafia humanos a romper redes de opressão; aproveita a riqueza da linguagem metafórica, sem perder a rigorosidade, para ajudar as pessoas a entenderem a história e praticarem ações para fazer do mundo lugar belo para viver.

Balduino - Gomercindo, perante a boniteza da utopia que acabas de enunciar, iríamos longe, nos perguntando como enfrentar esta nossa civilização do "descartável", pobre ou privada quase inteiramente de "conteúdo humano", que levou muitos pensadores e pensadoras do nosso tempo a vê-la caracterizada pela 
"barbárie", ou até mesmo como "anticivilização da barbárie". Esses autores e a fenomenologia do nosso mundo, retratado a cada dia na mídia, levou-me a pesquisar e a escrever sobre o que eu denomino "Pedagogia das grandes urgências", título ao qual eu acrescento, como contraponto, "e das grandes convergências". Na perspectiva das convergências, eu cito, na Carta-prefácio a Pedagogia da indignação (Andreola, 2000, p. 25), mais de vinte personalidades do nosso tempo, que, em contextos muito diferentes, se dedicaram, ao longo de toda a sua vida, à luta pela construção de um mundo mais humano e solidário. Paulo Freire, eu o vejo na constelação ampla dessas e muitas outras personalidades, nos diferentes campos do conhecimento e da ação humana, que comungam nesse propósito da solidariedade humana. Nesse sentido, eu considero que Pedagogia do oprimido não é apenas o livro mais importante de Paulo Freire, mas um projeto que já não pertence a ele, há muito tempo, porque recriado, de diferentes formas, no mundo inteiro, por milhares de educadores e milhões de pessoas, em escolas, universidades, igrejas, organizações comunitárias e movimentos sociais. Essa constelação de convergências de grandes educadores e educadoras de nosso tempo, entre eles, Paulo Freire, nos animam a acreditar que um mundo mais belo é possível, e que, por isso, vale a pena não desistir da grande marcha da libertação.

No contexto das manifestações ou "marchas" populares que o Brasil viveu no mês de julho deste ano de 2013, eu vejo a Jornada Mundial da Juventude, como uma "marcha global", imensa, da juventude do mundo inteiro, contra a "globalização da indiferença" e contra a "idolatria do dinheiro", contravalores denunciados pelo papa Francisco. Ele expressou uma grande confiança nos jovens, ao declarar:

[...] um jovem que não protesta não me agrada. Porque o jovem tem a ilusão da utopia, e a utopia não é sempre ruim. A utopia é respirar e olhar adiante. [...] É preciso ouvir os jovens, dar-lhes lugares para se expressar e cuidar para que não sejam manipulados. (PAPA FRANCISCO, 2013)

Quem sabe, possam ser os jovens os pioneiros de uma "reinvenção da pedagogia", como "pedagogia do encontro" e como uma experiência exemplar da "cultura do encontro em todo o mundo" - segundo as palavras do papa Francisco. Nisso, Freire é atualíssimo. As cento e cinquenta viagens internacionais dele, durante os dez anos do Conselho Mundial de Igrejas, acrescentadas às dezenas ou centenas de outras, somando as do exílio chileno, com as que vieram antes e depois do exílio, conferem-lhe uma legitimidade incomparável para a declaração que ele fez 
na famosa entrevista publicada no Pasquim: "Eu sou capaz de querer bem, enormemente, a qualquer povo" (FREIRE, 1978, p. 10). Penso que cabe mais uma frase tua para fechar o texto, após a citação.

Depois de citarmos a mensagem de esperança do papa Francisco, na Jornada da Juventude, reafirmada em sua Carta Encíclica Evangelii Gaudium, e a proclamação amorosa de Paulo Freire, podemos concluir citando um outro líder mundial, Nelson Mandela, que nos deixou o testemunho de uma vida inteira de que vale a pena lutarmos para a construção de um mundo mais belo e solidário.

\section{Referências Bibliográficas}

ANDREOLA, Balduino Antonio. Ernani Maria Fiori: um filósofo comprometido com a práxis histórica. In. DALBOSCO, Claudio A.; TROMBETTA, Gerson L.; LONGHI, Solange M. (Org.). Sobre filosofia e educação: subjetividade - intersubjetividade na fundamentação da práxis pedagógica. Passo Fundo: Universitária, 2004. p. 214-229.

A universidade e o colonialismo denunciado por Fanon, Freire e Sartre. In. Cadernos de educação, ano 16, n.29, p. 45-72, jul-dez 2007.

. Carta-Prefácio a Paulo Freire. In. FREIRE, Paulo.

Pedagogia da Indignação: cartas pedagógicas e outros escritos. São Paulo: editora UNESP, 2000. p. 15-25.

; RIBEIRO, Mario Bueno. Andarilho da esperança:

Paulo Freire no Conselho Mundial de Igrejas. São Paulo: ASTE, 2005.

CARDOSO, Fernando Henrique. Pensadores que inventaram o Brasil. São Paulo: Companhia das Letras, 2013.

COUTINHO, Afranio. O grande Anísio. Apresentação. In. TEIXEIRA, Anisio. Educação não é privilégio. 6ª ed. organizada e comentada por Marisa Cassim. Rio de Janeiro: Ed. UFRJ, 1999. p. 13-14.

DOMENACH, Jean-Marie. Mounier dépassé? In. Esprit: Paris, 1970.

FREIRE, Paulo. Depoimento. In. ANDREOLA, Balduino A. O Instituto de Cultura Popular do Rio Grande do Sul: Relatório de Pesquisa enviado ao CNPq. Porto Alegre: Faculdade de Educação da UFRGS, 1995.

. Pedagogia da autonomia: saberes necessários à prática educativa.

São Paulo: Paz e Terra, 1997.

Pedagogia da indignação: Cartas pedagógicas e outros escritos.

São Paulo: Editora UNESP, 2000.

GANNE, Pierre. Introduction à la lecture d'Emmasnuel Mounier. Grenoble: Centre Catholique Universitaire, Polycopié, s/date.

Pour um portrait spirituel d'Emmanuel Mounier. Eglise de Grenoble, bi-mensuel, (14), p. 425-28, avr. 1975. In. ANDREOLA, Balduino Antonio. Emmanuel 
Mounier et Paulo Freire: une pédagogie de la persone et de la communauté. Louvain-la-Neuve, 1985. Tese (Doutorado em Ciências da Educação) - Université Catholique de Louvain. Faculté de psychologie et des sciences de l'Education. Louvain-la-Neuve, 1985. p. 75.

GARAUDY, Roger. Para um diálogo das civilizações: o ocidente é um acidente. Lisboa: Editorial Império, 1977.

GEERTZ, Clifford. A interpretação das culturas. Rio de Janeiro: LTC, 1989.

MCLAREN, Peter. A pedagogia da possibilidade de Paulo Freire. In. Educação, Sociedade \& Culturas. Paulo Freire, n.10, p. 57-82,1998.

MCLAREN, Peter. Utopias provisórias: as pedagogias críticas num cenário póscolonial. Petrópolis: Vozes, 1999.

MOUNIER, Emmanuel. La Pensée de Charles Péguy. In. Oeuvres. Paris: Deuil, 1961. Tome I.

PAPA FRANCISCO. Um jovem que não protesta não me agrada. Disponível em: http://odia.ig.com.br/noticia/jornadamundialdajuventude/2013-07-29/um-jovem-quenao-protesta-nao-me-agrada-diz-papa-francisco-em-entrevista.html. Acesso em: 17/12/2013.

PAULO Freire, no Exílio, ficou mais brasileiro ainda. Entrevista com Claudius Ceccon e Miguel Darcy de Oliveira. O Pasquim, n. 462, p. 07-11, 1978.

RIBEIRO, Mario Bueno. Andarilhagens pelo mundo: Paulo Freire no Conselho Mundial de Igrejas CMI. São Leopoldo, 2009 Tese (Doutorado em Teologia) - Escola Superior de Teologia - Instituto Ecumênico de Pós-Graduação em Teologia. São Leopoldo, 2009.

RIBEIRO, Darcy. Universidade para quê?. Brasília: Editora da Universidade de Brasília. 1984.

RICOEUR, Paul. A memória, a história, o esquecimento. Campinas: Editora da Unicamp, 2007.

TORRES, João Carlos. Depoimento em mesa-redonda. In. ANDREOLA, Balduino A.. O Instituto de Cultura Popular do Rio Grande do Sul: Relatório de Pesquisa enviado ao CNPq. Porto Alegre: Faculdade de Educação da UFRGS, 1995. 